\title{
SINCRONÍAS TRANSATLÁNTICAS DEL MODERNISMO: POLIFONÍA E ITINERARIOS EN LA REVISTA PEGASO (MÉXICO 1917)
}

\author{
POR \\ JosÉ MARÍA MARTÍNEZ \\ The University of Texas-Pan American
}

Aunque los estudios transatlánticos sobre el mundo hispánico no tienen una tradición tan larga ni son tan numerosos como los dedicados al anglosajón, poco a poco van mostrando su peso real y creciente en esta empresa hermenéutica y denunciando implícitamente la marginalidad en que los recluyó el discurso hegemónico. Como consecuencia, y de manera análoga a lo ocurrido con la inclusión del "Black Atlantic" en este debate, su presencia está generando la relectura de toda la interacción transatlántica, interacción que ahora ha de verse forzosamente multidireccional, multidimensional y multiétnica. ${ }^{1}$ Los encuentros y volúmenes coordinados por Julio Ortega (México, Nuevos hispanismos), Pérez de Mendiola (Bridging), la Universidad de Brown o el proyecto Letral, así como los monográficos editados por Nina Gerassi-Navarro y Eyda E. Merediz, por Joseba Gabilondo ("Introduction”), por Pérez de Mendiola (“Going"), o por Francisco Pérez de Alba y Pedro Pérez del Solar, están mostrando claramente esa heterogénea pluralidad y a la vez abriendo una ingente cantidad de caminos y motivos críticos que discurren también acordes al fenómeno de la globalización y que están renovando la lectura de las relaciones interculturales de los diversos núcleos conectados por el Atlántico.

Como generalmente muestran este tipo de trabajos sus aportaciones rebasan ya el reduccionismo en el que habían caído algunos esencialismos teóricos y alguno enfoques propios de los estudios culturales (Ortega, México 10), y están proporcionando a esas aproximaciones un tono de apertura y libertad que aunque a veces corre el riesgo de la excesiva dispersión también permite una lectura unificada y relacional de manifestaciones culturales heterogéneas o divergentes. Quizá como pocas veces hasta ahora esa producción cultural se está enmarcando en contextos diversos y numerosos, y quizá también pocas veces como ahora estos análisis están insistiendo en la multiplicidad efectiva de factores, en la anulación de jerarquías, en la transcontinentalidad y multinacionalidad de los

Afortunadamente, esta perspectiva globalizadora es la que también parece ir abriéndose camino en los estudios más recientes publicados en el ámbito anglosajón (ver por ejemplo Manning y Taylor). 
productos culturales y literarios hispánicos y en la simultánea interacción de esa cultura y esa literatura con otro tipo de discursos. Los trabajos antes aludidos son una buena muestra de esa "unificada heterogeneidad" que caracteriza y mueve a estos estudios. Por recordar algunos ejemplos más donde este enfoque se aplica a productos o relaciones dispares, pueden mencionarse los trabajos sobre la política lingüística subyacente en la Exposición Universal de 1992, en la creación del Instituto Cervantes o en la revista Cuadernos Hispanoamericanos (Pérez de Mendiola, "The Universal"; Escudero), el rezago eurocéntrico que sigue pesando en la propia crítica trasatlántica (Gabilondo, "Genealogía"). En un ámbito más literario, cabe recordar la inestabilidad identitaria provocada por la figura recurrente del indiano en la España del XIX (Fernández), las variaciones transatlánticas del 'topos' de la peregrinación clásica y su relación con la modernidad (Chemris), o las inquietudes transoceánicas de figuras como Cervantes o Sor Juana (Ortega, "Cervantes"). La revisión de jerarquías se ejemplifican por un lado en la temprana autonomía de las autorrepresentaciones americanas frente a las europeas (Voigt), en el rol de centro que llega a adquirir la Colonia en algunos momentos (Fuchs y Martínez-San Miguel), pero también, en dirección inversa, cuando la figura peninsular del cacique se propone como posible referente para la figura del dictador latinoamericano (Gibbs), o cuando, tras la emancipación, los valores de la antigua metrópoli se recuperan para reivindicar las distancias frente a lo anglosajón (Stevens Arroyo). En un plano más político encuentran los análisis de las discrepancias decimonónicas americanas a la hora de evaluar su hispanismo (Katra, Delaney), la labor diplomática transcontinental de autores como Alfonso Reyes (Castañón) o la dinámica de los discursos dictatoriales en ambas orillas delAtlántico (Gutiérrez Mouat). Igualmente interesantes son esas proyecciones de lo cisatlántico más allá del mundo hispánico, ${ }^{2}$ como se ve en la dinámica transnacional de las producciones cinematográficas y televisivas hispanoamericanas (Smith) o las múltiples conversaciones e intercambios con el mundo anglosajón (Bauer, Gerassi, Hill, Ita). Finalmente puede recordarse destacar los análisis sobre las particularidades de los espacios insulares atlánticos (Merediz), y, en el plano del mercado crítico y creativo, los trasiegos y políticas editoriales entre España y América Latina (Letral).

Obviamente y como muestra este pequeño corpus crítico, los campos pendientes pueden multiplicarse casi hasta el infinito y enriquecer las propuestas pioneras de Julio Ortega, que veían en la Colonia, las traducciones, el exilio y las vanguardias, los ámbitos preferenciales para la aplicación de este tipo de análisis. Además de éstos y de los arriba señalados otros que a mi juicio necesitan esta lectura de forma más o menos perentoria serían la inserción del "Black Atlantic" en la dinámica hispánica (y viceversa), la representación de la emancipación en ambos lados delAtlántico, la recepción

\footnotetext{
2 Empleo el término "cisatlántico", en el sentido que le da Armitage, es decir, lo nacional o lo regional
} entendido en un contexto atlántico.

Revista Iberoamericana, Vol. LXXIX, Núms. 244-245, Julio-Diciembre 2013, 929-947 ISSN 0034-9631 (Impreso) ISSN 2154-4794 (Electrónico) transatlántica del boom, o la dimensión transatlántica de escritores contemporáneos como Mario Vargas Llosa, Roberto Bolaño o Andrés Neuman, que tienen en ella una de sus principales marcas de identidad. ${ }^{3}$

En todo este contexto me interesa también ahondar en otro momento cultural -el Modernismo- que ya ha sido producto de varios análisis explícita o implícitamente transatlánticos, pero que creo que todavía tiene mucho que aportar a este debate. De hecho, según mi recuento personal, la bibliografía al respecto le coloca a la cabeza de los momentos literarios canónicos, por encima incluso de la Colonia o las vanguardias. Quizá esto sea un primer indicador de que se trata un periodo crucial en los intercambios transatlánticos hispánicos. Razones para ello no faltan, pues a la desaparición del antiespañolismo que siguió a las décadas posteriores a la emancipación, sucedieron luego efemérides y fechas como 1892 o 1898, que hicieron desaparecer muchas de esas distancias y crearon nuevas y más intensas formas de interacción. A ello se añade, de forma intensa y determinante, la inicial globalización del capitalismo que hace arribar de forma masiva y general todo tipo de productos y mercancías a América Latina no sólo desde muchos de los países de la otra orilla del Atlántico sino también desde Estados Unidos, es decir, desde el mundo cisatlántico no hispánico. De forma muy diferente a los años coloniales o a las primeras siete décadas del XIX, el fin de siècle supone pues una intensa fluidez e interacción entre América Latina y las diferentes parcelas geopolíticas y culturales del ámbito atlántico. No debe resultar extraño entonces que ya antes de la inauguración de la crítica explícitamente transatlántica contase con estudios como el de Donald F. Fogelquist (Españoles de América y americanos de España) o el de Ignacio Zuleta (La polémica modernista: el modernismo de mar a mar) donde esta dimensión aparecía ya como componente esencial de la literatura hispánica del fin de siglo. Por si hicieran falta más datos, a esos dos títulos podrían añadirse creaciones como Los raros, España contemporánea o Peregrinaciones, todas ellas de Rubén Darío.

En cuanto a la crítica más reciente acerca del Modernismo Alberto Acereda se ha ocupado ya de la interacción entre literatura y artes plásticas así como de la reacción antimodernista que a la vez unifica el modernismo de ambas orillas. Por su lado Ericka Beckman y Juan Pablo Dabove han analizado sus correlaciones con el mundo literario y mercantil anglosajón y José Luis Venegas se ha preocupado de comentar cómo la literatura epistolar de Unamuno con América responde a una relectura de su concepto de Hispanidad, que es tan transatlántico como hispanoamericano. Por su parte José Ismael Gutiérrez ha comentando la transculturación que conllevan las traducciones hispanoamericanas de originales europeos y, más recientemente, Alejandro MejíasLópez ha dedicado una extensa monografía proponiendo el Modernismo latinoamericano como uno de los principales catalizadores de la literatura peninsular contemporánea.

Otras sugerencias, menos relacionadas con lo estrictamente literario, pueden verse también en Faber 338

17. Revista Iberoamericana, Vol. LXXIX, Núms. 244-245, Julio-Diciembre 2013, 929-947 ISSN 0034-9631 (Impreso ISSN 2154-4794 (Electrónico) 
El camino que he elegido yo-el análisis transatlántico de la revista Pegaso (México, 1917) - no es enteramente nuevo, pues ya Adela Pineda se ha ocupado de comentar algunas de las publicaciones modernistas más conocidas, como fueron la Revista de América (Buenos Aires 1894), La Revista Azul (México 1894-1896), el Mercure de France (París 1890-1911) y la Revista Moderna (México 1898-1911). ${ }^{4}$ Aunque la perspectiva transatlántica está implícitamente presente en su estudio, Pineda persigue principalmente describir la política cultural y literaria de las revistas volcada hacia el mercado y la política latinoamericana y al final la multiplicidad de discursos e itinerarios que definen su carácter transoceánico sólo pueden quedar ligeramente apuntada. Como resultado, el carácter y alcance transcontinental de las revistas aparece realmente reducido y no hace completo mérito a su pluralidad discursiva y direccional. Por otro lado, la orientación específica de algunas de esas publicaciones limitaba también un análisis abierto y plural. Como primer ejemplo la Revista de América se presentaba con una declaración de propósitos fundamentalmente esteticista, en la que pretendía ser "el órgano de la generación nueva que en América profesa el culto del arte puro, y desea y busca la perfección ideal" (Carter 45). Por su lado, Manuel Gutiérrez Nájera, a presentar la Revista Azul afirmaba que el Arte era el "Príncipe y Señor" de los editores de la revista, "porque el arte descifra y lee en voz alta el poema vivificante de la tierra y la harmonía (sic) del movimiento del espacio" (534). Frente a ellas Pegaso llevaba el subtítulo de "Revista Ilustrada" y se presentaba a sí misma como una "Revista Ilustrada de Literatura y Actualidades" (I:150) y también como "La más selecta revista literaria de actualidades que ahora se publica en México" (I:151). ${ }^{5}$ Sintomático es, en este sentido, que la revista no cuente con una declaración de principios estéticos, y desde su primer número lleve como subtítulo "Revista Ilustrada".

\footnotetext{
Lo que sí resulta llamativo es la escasa o nula atención que los estudios transatlánticos han prestado a la prensa periódica. Y es que ésta constituye un repertorio inigualable para notar convivencia de discursos heterogéneos y la constatación de itinerarios culturales e ideológicos simultáneos. Hasta donde llegan mi datos, el trabajo de Pineda es un análisis aislado en el caso del Modernismo hispánico, aunque el artículo de Acereda ("El antimodernismo...") descansa de forma principal sobre el material proporcionado por revistas y magazines de la época; para el ámbito anglosajón sólo he podido localizar el estudio de Snead citado en la bibliografía final, el cual aborda el tema desde la perspectiva de la estética de la recepción. Por supuesto, el discurso literario y libresco es uno de los principales, y, de hecho, otra de las definiciones que la publicación da de sí misma es la de ser "la revista de los intelectuales" (I.179). Sin embargo, aqui tratá de insirir en los discus extrater tratace de insir en los dicas te la de la edición facsimilar de la revista la presentan como una publicación "en la que conviven literatura, la información periodística, el comentario de espectáculos y de deportes, y las variedades de entretenimiento" (I:7). En cuanto a las citas de la revista y para facilitar su localización utilizaré aqu la paginación empleada en los dos volúmenes de los que consta esa edición facsimilar, bastante más accesible que la original.
}

Revista Iberoamericana, Vol. LXXIX, Núms. 244-245, Julio-Diciembre 2013, 929-947 ISSN 0034-9631 (Impreso) ISSN 2154-4794 (Electrónico)
Por lo mismo, mi análisis de Pegaso ha preferido atender a los aspectos y motivos que a mi juicio han quedado más bien relegados en los trabajos sobre las otras revistas finiseculares. Por un lado he querido insistir en el carácter plurilingüístico y polifónico de sus contenidos, en el sentido que Bahktin dio a estos términos al estudiar a Rabelais y Dostoyevsky (Problems 7-14, Esthétique 122-126). Resumiendo, Bakhtin propone por un lado la convivencia de diferentes niveles lingüísticos (del mismo idioma) como algo connatural en los textos humorísticos y subversivos y, por otro, la coexistencia e interacción de personajes y conciencias autónomos e independientes. Así consideradas no resulta difícil relacionar esas notas con revistas como Pegaso. Es decir la variedad de discursos (el periodístico, el histórico, el literario tanto en prosa como en verso, el publicitario, el código visual de las ilustraciones, etc.) van a comportar el funcionamiento del idioma en niveles diferentes que, obviamente, se corresponden con intereses editoriales diferentes, con tipos de lectores igualmente diferentes y con referentes temáticos también distintos. Por otro lado, la división de cada número de la revista en secciones claramente marcadas funcionan en su conjunto de acuerdo al concepto de polifonía que propone Bakhtin. Todas ellas son partes del mismo texto pero cada una de ellas remite a un campo autónomo y son capaces de adquirir una vida independiente fuera de ese texto. Como ejemplo están los poemas de Amado Nervo o de Enrique González Martínez que se incluyen en algunos números de la revista y que iban a aparecer o habían aparecido ya en volúmenes independientes, en formato de libro. En la misma línea se podría añadir la posibilidad de los editores de la revista de haber elaborado un volumen con los cuentos que se publicaban en ella con periodicidad semanal o con el vasto número de caricaturas y viñetas humorísticas referidas a la I Guerra Mundial. ${ }^{6}$ Como afirman Schwartz y Patiño, las revistas permiten la captación de discursos heterogéneos previos "[...] a su consolidación en ideologías culturales, en tanto conjunto articulado de ideas y valores. Este estado de movilidad del pensamiento y de la sensibilidad posibilita una serie de cruces diversos, novedosos e inclusive contradictorios, impensables a posteriori" (648, cursivas mías).

También interesa comentar Pegaso por motivos historiográficos. Al reevaluar el marbete de "Generación del '98", José Carlos Mainer afirmaba que una de las maneras de revitalizar los estudios sobre el fin de siglo hispánico era mediante el empleo de cortes sincrónicos distintos a los tradicionales (10). Aplicando esas propuestas al ámbito hispanoamericano, este tipo de cortes temporales sería igualmente útil y así, frente a las fechas habituales de 1888, de 1896, 1900 y 1905 (respectivamente las fechas de Azul...

\footnotetext{
En este sentido el número de secciones de la revista es relativamente amplio y temática y discursivamente heterogéneo. Como es propio de este tipo de publicaciones lo que en ellas ocurre es sobre todo un sincronización de discursos que responden a diferentes paradigmas de producción y recepción. Algunas de esas secciones serían: "Publicidad", "Crónica", "El cuento semanal", "Vida artística y literaria",
} "Teatros y cines", "Libros y revistas", "Poesía", "La actualidad política", "La Gran Guerra", etc.

17. Revista Iberoamericana, Vol. LXXIX, Núms. 244-245, Julio-Diciembre 2013, 929-947 ISSN 0034-9631 (Impreso) $\quad$ ISSN 2154-4794 (Electrónico) 
Prosas profanas y Los raros, Ariel y Cantos de vida y esperanza), proponer el corte de una fecha como la de 1917, con unos textos menos tópicos pero no menos elocuentes, reforzaría la visión heterogénea y poliédrica del Modernismo e incorporaría a la palestra la figura de otros escritores que estaban ocupando el espacio dejado por Rubén Darío (muerto en 1916), José Enrique Rodó (fallecido también en mayo de 1917) o por un Amado Nervo que ya parecía incapaz de evitar repetirse a sí mismo. En este sentido y aparte de los tres co-directores de la revista, en Pegaso van a aparecer también prosas y versos de autores jóvenes (Alfonso Reyes, Carlos Pellicer, Jaime Torres Bodet) en los que a veces siguen pesando el modernismo más tópico pero en los que también se apuntan las notas del posmodernismo e incluso las vanguardias. ${ }^{7}$

Esto implica insistir en la especial temporalidad de las revistas literarias y culturales. Por un lado, es evidente que cada número publicado implica una sincronización de sus contenidos, que así, aunque procedan de orígenes diversos o sean temáticamente heterogéneos (Schwartz 647-48), acaban creando una interdependencia mutua inexistente antes de su publicación y la posibilidad también de ser leídos en un mismo contexto Las revistas muestran también lo que Santiañez-Tió, en un trabajo pensado para sugerir nuevos caminos de estudios para la historia literaria, denominaba la transtemporalidad de la literatura (272), es decir la capacidad de ésta de perdurar y convivir en épocas diferentes a las de la creación de cada texto y a la posibilidad de éste de ser leído en formatos y circunstancias distintos a los que fue concebido. Pegaso recoge también esa transtemporalidad, aunque mirando más al futuro que al pasado. Lo habitual en sus páginas es la publicación adelantada de prosas y sobre todo poemas que posteriormente van a ser recogidos en formato de volumen. Simultáneamente también reproduce poemas y traducciones con publicación previa, como es el caso de algunos textos de Rubén Darío, de Amado Nervo, de Francis Jammes, Gabriela Mistral y -pasando a las artes plásticas-algunos cuadros de Antonio de la Gándara, o caricaturas políticas aparecidas recientemente en la prensa extranjera. De la misma manera, en secciones de la revista como la propiamente publicitaria, la linealidad temporal puede decirse que queda igualmente comprometida, pues un gran número de anuncios se repite idénticamente, sin cambio alguno, a lo largo de los sucesivos números de la revista, lo que en cierta manera niega la existencia del discurrir temporal ("el tiempo es la medida del cambio", decían los clásicos), y proporciona un elemento más de fijación identitaria a la revista, que en este sentido sigue siendo la misma a lo largo de toda su trayectoria. Por último, en Pegaso aparece también el discurso cronológico propiamente histórico o lineal, pues gran parte de su contenido internacional se dedica a informar del desarrollo y progreso

Una interesante síntesis de ambas tendencias sería el poema “Lawn Tennis”, de José Juan Tablada (II:36), donde el deporte, uno de los temas típicos del futurismo se llena de alusiones a la mitología clásica y dispone sus versos en una manera que evoca a los caligramas de Apollinaire o, incluso, a cierta poesía visual.

Z7) Revista Iberoamericana, Vol. LXXIX, Núms. 244-245, Julio-Diciembre 2013, 929-947 ISSN 0034-9631 (Impreso) ISSN 2154-4794 (Electrónico) de la I Guerra Mundial, y al inicio y primeros momentos de la revolución rusa. De esta forma la revista es también una revista de la actualidad caduca y pasajera, muy distinta de la sincrónica y la transtemporal que hemos marcado antes y, por todo ello, acorde con aquellas premisas de los estudios transatlánticos que mencionábamos al comienzo y que permitían la conexión de instancias culturales de ambos lados del Atlántico bien fueran simultáneas, sucesivas o cronológicamente fragmentadas.

Si algún reparo merecen las propuestas transatlánticas es la insistencia de alguna de ellas en su inherente relativismo, frente al esencialismo en el que al final habrían acabado las hermenéuticas teóricas y también los estudios culturales. El hecho de que esas mismas orientaciones (deconstrucción, feminismo, etc.) pretendieran un antiesencialismo radical que al final reveló su imposibilidad práctica (Quevedo, Colebrook, Champagne, Golubov, Patai), debería llevar a los "transatlanticistas" a un tipo de afirmaciones menos precipitadas. El caso de los "Scottish Studies", tal como lo presenta Gavin Miller, puede convertirse en un claro precedente, pues en su pretensión por liberarse del antiguo esencialismo monolítico han acabado cayendo en un nuevo esencialismo que no sería monolítico por no ser monocultural, pero sí lo sería en el momento en que puede definirse establemente como heterogéneo o multicultural. El hecho de que sus componentes internos varíen o cambien con el tiempo o con el enfoque correspondería más bien con lo que la metafísica clásica llamaría accidentes de la esencia, es decir con los componentes de esa naturaleza estable que les permite seguir recibiendo la denominación de 'Scottish' mientras siguen unidos a ella, pero que les permite desprenderse de tal adjetivo una vez que pasan a fijarse en otra instancia esencial. Algo parecido puede entonces pasar con los estudios transatlánticos. No cabe negar que esos enfoques descubren un panorama altamente heterogéneo de discursos, itinerarios y temporalidades, pero tampoco cabe identificar esa extremada fluidez o movilidad accidental con su naturaleza u origen más hondos. Volveríamos a caer en lo que se ha llamado la falacia de Heráclito, que al afirmar la imposibilidad de "bañarse dos veces en el mismo río" estaba confundiendo el agua con el río, la parte con el todo. Tampoco podemos caer en la falaz pretensión del relativismo absoluto, porque cuando propone "todo es relativo" está ya instaurando una certidumbre universal (que "todo es relativo"; cursivas mías). La verdad es que el antiesencialismo transatlántico tampoco tiene una salida fácil. Desde el momento en que se vincula a un espacio geopolítico concreto y estable (lo que es fluido o heterogéneo no es ese espacio en sí, sino las relaciones e intercambios que se producen entre sus diversas instancias internas), queda ya diferenciado de otros ámbitos análogos (los estudios latinoamericanos, por ejemplo) cuyas relaciones e itinerarios no podrían recibir el adjetivo de 'atlánticos' a no ser de manera heteróloga. Y me parece que esta posibilidad de la exclusión implica necesariamente la existencia de un sustrato fijo y fundacional, de una esencia que sustenta toda esa rica fluidez y heterogeneidad accidental a la que se refieren los estudios mencionados al comienzo, también este mismo, y todos los que faltan por venir. Su movilidad o su heterogeneidad

Revista Iberoamericana, Vol. LXXIX, Núms. 244-245, Julio-Diciembre 2013, 929-947 ISSN 0034-9631 (Impreso) ISSN 2154-4794 (Electrónico) 
son marcas accidentales, como lo sería el cambio para el dios Proteo, una marca que no sería propia de otros dioses. La tarea más bien consistiría en determinar qué es lo que constituye el sustrato permanente de esos estudios, sustrato que de una manera u otra al final va a definirse en una dependencia inevitable del espacio geográfico en torno al cual se producen todas esas interacciones. La forma de entender las correlaciones entre ese sustrato y los movimientos que en él se sostienen será probablemente lo que defina el grado de estabilidad metafísica o esencial de la hermenéutica trasatlántica.

En cuanto a Pegaso, la revista vio la luz a comienzos de 1917, se publicó con una periodicidad más o menos semanal, y acabó extinguiéndose a mediados de julio de 1917, con un total de veinte números publicados. El principal promotor y uno de sus fundadores y directores fue Enrique González Martínez, al que se unieron Efrén Rebolledo y Ramón López Velarde. Los tres se mantuvieron al frente de la misma hasta el décimo número, en que pasan a figurar como redactores y a partir del cual son sustituidos en las tareas de dirección por Jesús B. González, que previamente había fungido como gerente. Entre sus redactores fijos aparecían Jesús Urueta, Antonio Castro Leal, Julio Torri, Jesús Villalpando y Jenaro Estrada, es decir, un grupo heterogéneo de escritores e intelectuales de edades y proyecciones políticas y culturales diferentes, que van desde la pertenencia al Ateneo de la Juventud, hasta la militancia antimaderista o protagonistas de carreras principalmente educativas o diplomáticas. Por el tipo de publicidad y noticias que contiene, y su formato lujoso la revista parece dirigirse a las clases pudientes y grupos intelectuales de la capital mexicana. Están ausentes, por ejemplo, todo tipo de crítica agresiva -y en realidad de casi todo tipo de crítica- hacia la vida política mexicana del momento $y$, en ese sentido, su atención se centra en las noticias sobre la Primera Guerra Mundial, donde la revista toma una clara postura a favor de los aliados. En su conjunto, no es una publicación que sobresalga por la excelencia de sus páginas literarias -que tampoco hay que desdeñar-pero, al mismo tiempo es lo suficientemente permeable y cuenta con la suficiente capacidad de convocatoria como para dejar registrado claramente lo que fue el zeitgeist del momento.

Aunque podría presentarse con otro formato, ${ }^{8}$ al resumir a continuación las “entradas

8 Uno de los borradores previos de este trabajo consistió en un índice temático de la revista, es decir en un listado de aquellas entradas que incluían lo transatlántico en cualquiera de sus manifestaciones. Con ello se pretendía romper la visión ofrecida para las revistas modernistas de índices tradicionales (Celma Valero, Díaz Alejo, Valdés), útiles pero casi siempre organizados cronológicamente o por orden alfabético de autores, lo cual, en la línea de las sugerencias de José Carlos Mainer y Nil Santiañez-Tió ya mencionadas, en poco ayuda a la renovación de la crítica del Modernismo. Por el contrario, ese índice trastlántico evide la posibilidad de una lectura nueva y transversal - Po auto

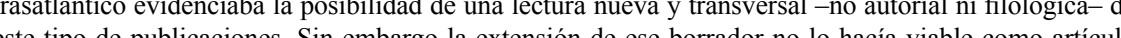
exte te to académico y al final se decidio por otro tipo de formato. Lo que sí hay que destacar son los resultados de ese indice, tanto por al alto núneco de entadas que resultaron al final como por la claridad con la que mostraban la inserción de lo transatlántico en prácticamente todas las secciones de la revista (aprox. un

Revista Iberoamericana, Vol. LXXIX, Núms. 244-245, Julio-Diciembre 2013, 929-947 ISSN 0034-9631 (Impreso) ISSN 2154-4794 (Electrónico) transatlánticas" de la revista he querido hacerlo insistiendo por un lado en la fluidez y heterogeneidad de sus contenidos y por otro en la ruptura de esquemas binarios aparición de triangulaciones de diverso tipo que se dan en la revista, para así mostrar e carácter abierto y múltiple de la misma y también el subyacente protagonismo del espacio atlántico, que figura como mediador geopolítico y geocultural en esas transacciones, bien sea en su ámbito cisatlántico (Latinoamérica y Estados Unidos) o en su dimensión transoceánico. ${ }^{9}$ Por tratarse de un resumen elimino repeticiones y recurrencias, las cuales por otro lado, no deben entenderse como redundantes sino como una muestra más del profundo carácter transatlántico de la revista.

Aunque aquí me voy a fijar tanto en lo literario como en lo extraliterario y aunque los propios editores no concibieron la revista como una publicación principalmente libresca, sí debe resaltarse que ese contenido constituye hasta cierto punto el nervio temático de la misma, aunque no en la proporción de la Revista de América o la Revista Azul. Como punto de partida queda claro que el modernismo literario de Pegaso-como el Modernismo en general-no es un momento castizo o introvertido, sino que despliega una amplia red de relaciones y prácticas más allá del mundo hispánico y de la literatura en español. Este cosmopolitismo tan propio del fin de siècle lo ratifican por ejemplo la publicación de traducciones de Francis Jammes, J. Gauthier, Aloysious Bertrand, Jules Lemaitre, G.K. Chesterton, Pierre Loti o Eça de Queiroz. También hay que notar las reseñas como la dedicada a Gabrielle D'Annunzio, o artículos como el que Ramiro de Maeztu dedica a la revolución rusa o el que Salvador de Madariaga publica sobre la cuestión de la nacionalidad irlandesa. En cuanto a lo cisatlántico podrían mencionarse la reproducción de un poema inédito de Rubén Darío, las noticias y retratos relacionados con la visita de Manuel Ugarte a México para promocionar el panamericanismo, o las noticias y homenajes referidos a la muerte de José Enrique Rodó.

Pero, al mismo tiempo, el corte temporal ofrecido por la revista muestra un modernismo muy diferente al de las revistas canónicas mencionadas anteriormente. Frente a la presencia en éstas de figuras normativas y capitalizadoras como Rubén Darío, Gómez Carrillo o Amado Nervo, en Pegaso aparecen como referentes principales

95\%). Lo que sigue a continuación es una reelaboración de ese índice a la luz de las notas teóricas con las que he dado inicio al artículo.

Por razones de espacio voy a obviar las referencias a artículos o secciones exclusivamente mexicanas. Reconozco que esta omisión puede considerarse incluso grave, pues es en México, a través de Pegaso, en donde convergen todas las trayectorias cis- y transatlánticas que se recogen en esos textos. Como ya se ha dicho, las revistas funcionan como centros normativos y centrípetos de todos los discursos que en ellas se contienen, incluyendo también algo tan multidireccional como lo transatlántico. De esta manera Pegaso se convertiría en la materialización textual de esa multiplicidad de discursos e itinerarios. Igualmente, por razones de espacio y salvo el caso de las citas literales, voy a omitir la paginación de las entradas de la revista a la que me esté refiriendo. Para ello remito al lector a los índices finales de la edición facsimilar de la revista, muy fáciles de manejar. 
Enrique González Martínez, Ramón López Velarde y Efrén Rebolledo, es decir, figuras que la historiografía modernista posterior ha solido ubicar más o menos injustamente en lugares marginales del modernismo o en un "modernismo de salida". En su conjunto Pegaso contiene por un lado la recuperación ocasional y en tono triunfalista de algunos textos de Amado Nervo, Leopoldo Lugones o Rubén Darío, pero también la aparición y promoción de textos de los tres co-directores, y secciones como la de "Poemas inéditos", donde los poetas más jóvenes, como Carlos Pellicer o Jaime Torres Bodet, tratan unas veces de seguir el modernismo más tópico y otras de apuntar nuevas orientaciones literarias. Así pues, en Pegaso conviven textos de modernistas normativos con otros de modernistas secundarios y otros de poetas que van a ver y protagonizar la desaparición de esa literatura y la llegada de las vanguardias. Contrastar este contenido literario con el de las revistas comentadas por Pineda, nos ofrece la imagen de un modernismo nada monolítico y más bien fragmentado, pero también vivo y autónomo, lleno de polifonías.

De la misma manera, en la historiografía del Modernismo han sido y siguen siendo frecuentes las polémicas acerca de la prioridad cronológica o jerárquica del fin de siglo peninsular o del hispanoamericano. Frente a esas interpretaciones que podemos llamar "verticales" Pegaso mostraría más bien que ambos lados del Atlántico se mueven en niveles simbióticos y unitarios. Por un lado aparecen esos autores mexicanos como Amado Nervo, Luis G. Urbina o el joven Alfonso Reyes que se instalan en España, o publican y son reconocidos en la Península, y por otro los casos de españoles como Salvador Rueda, Francisco Villaespesa o Eduardo Zamacois que viajan a México promocionar sus obras y donde son igualmente reconocidos y homenajeados. En dicho sentido Pegaso realmente ofrece la impresión de un modernismo no heterotópico sino más bien homogéneo y horizontal y, en lo que nos interesa, ejemplarmente transatlántico.

Mención aparte merecen las prácticas y el mundo editoriales, esa elocuente combinación del discurso mercantil y el propiamente artístico. En Pegaso ello se da unas veces directamente, en las páginas dedicadas a la publicidad, y otras indirectamente, con reseñas y notas que aparecen en secciones como "Libros y revistas" o "Vida literaria y artística". También aquí quedan registrados los intercambios transoceánicos. Por un lado se recogen, reseñan o reproducen las publicaciones llevadas a cabo por autores mexicanos e hispanoamericanos en España, y por otro se llenan las páginas de publicidad con anuncios de librerías mexicanas de origen nacional (Porrúa, Botas, Atenea) o foráneo (Bouret) que ponen a la venta obras de autores peninsulares contemporáneos -éstas habitualmente de forma privilegiada-y también de escritores mexicanos, sudamericanos, estadounidenses y europeos. Igualmente se anuncian suscripciones a varias revistas culturales que, o bien contienen colaboraciones habituales de autores españoles e hispanoamericanos, o bien son dirigidas por dos o tres intelectuales de diferentes nacionalidades. Hay que notar también que este tipo de publicidad se intensifica o se modela también en función de circunstancias de actualidad, como puede ser la muerte ISSN 0034-9631 (Impreso)

Vol. LXXIX, Núms. 244-245, Julio-Diciembre 2013, 929-947 ISSN 2154-4794 (Electrónico) o la visita a México de alguno de esos escritores (Villaespesa, Ugarte). Finalmente, una interesante muestra de esta simbiosis, y también de la transtemporalidad y relativismo de las ordenaciones cronológicas y estéticas de la historia literaria se sintetizaría en los anuncios de la popular colección "La novela corta", de origen peninsular, en la librería Botas, en los que se ofrecen narraciones de autores tanto peninsulares como latinoamericanos y tanto modernistas como realistas, entre otros Villaespesa, Galdós, Nervo, Vargas Vila, Trigo, Pardo Bazán, etc.

Pasando ahora a la información editorial de la propia revista, debe notarse que a partir de su cuarto número se listan los países de trabajo de los colaboradores que no residen en México. Entre esos colaboradores se encuentran Jesús T. Acevedo en El Paso (EE.UU.), Francisco de Icaza, Pablo Martínez del Río, Amado Nervo, Alfonso Reyes y Manuel Romero de los Terreros en Madrid; Leopoldo de la Rosa y Salomón de la Selva en Nueva York, Adrián Recinos en San José de Guatemala, y José Vasconcelos en Perú. Con algunos cambios mínimos en la lista los destinos de colaboradores se mantienen hasta el último número, de la misma manera que en todos los números se ofrece la posibilidad de suscribirse desde el extranjero. A parte de esos colaboradores, de los cuales unos llegan realmente a colaborar (Alfonso Reyes, Amado Nervo) y otros no (José Vasconcelos), aparecen también contribuciones de nombres ausentes que escriben tanto desde algún país de América Latina, como Eduardo Colín (Guatemala), como desde España (Ramiro de Maeztu). En conjunto, y aunque la mayor parte de los textos están firmados por autores mexicanos residentes en el país, el porcentaje de autores foráneos o de nacionales residentes en el extranjero tampoco es excesivamente bajo. Todo esto, en su conjunto evidencia de nuevo ese alcance trasatlántico de la revista, esta vez en su dimensión más propiamente administrativa o de producto empresarial.

Otro apartado diferente lo constituirían las portadas de cada número de la revista, que siempre son ilustraciones monotemáticas, y que en ocasiones se refieren a motivos o personajes locales pero que en su mayoría lo hacen a asuntos foráneos, bien sean cisatlánticos o transatlánticos, hispánicos o no hispánicos. Algunos ejemplos serían las dedicadas al presidente estadounidense, Woodrow Wilson, "el hombre del día" (I:129), a los "Submarinos americanos listos para entrar en acción" (I:153), al "general Nivelle, que dirige la gran ofensiva francesa" (I:173) o a los "Soldados escoceses volviendo del combate" (I:221). Otras portadas las ocupan "El poeta español Francisco Villaespesa" (I:285), "Antonia Merce. Notable bailarina [española] que actualmente trabaja en el Teatro Colón" (I:325), "El inventor Marconi en traje de Subteniente de Ingenieros de la Armada Italiana" (II:9); "El Arco del Triunfo (París), II:49); o el "Retrato de Ida Rubinstein, porAntonio de la Gándara"(II:89). Como puede notarse, las portadas y lo que conllevan de discurso gráfico y código visual, se inscriben también en los movimientos transatlánticos de la revista, pero en este caso, más obviamente que en los mencionados antes, esos movimientos e intereses van más allá del mundo hispánico y principalmente vinculan a la revista, a México, y al Modernismo, con toda la escena política europea.

Revista Iberoamericana, Vol. LXXIX, Núms. 244-245, Julio-Diciembre 2013, 929-947 ISSN 0034-9631 (Impreso) ISSN 2154-4794 (Electrónico) 
Como muestran los títulos de las portadas, otro de los principales contenidos transatlánticos de Pegaso, va a ser el referido a la Primera Guerra Mundial, que sin duda es el asunto político que más espacio ocupa en la revista. De ella se dan noticias desde el primer número hasta el último, cuenta con una sección propia titulada "La Gran Guerra", y seguramente es, después de la publicidad, el asunto que más páginas se lleva del total de la publicación. Los itinerarios y trayectorias transatlánticas o cisatlánticas desplegadas en este contexto concreto son múltiples. En primer lugar tenemos la atención de la revista al fenómeno bélico en sí, cuyo principal escenario está ubicado en la otra orilla del Atlántico y que hace que sus páginas se llenen de referencias nominales, culturales o políticas a ese ámbito transoceánico. Por otro lado se da también una vinculación con la propia demografía mexicana, pues como dejan claro otras secciones y otras noticias, entre esa población se encuentran también colonias francesas, italianas, inglesas o estadounidenses, que obviamente van a acercarse a esa noticia con una especial e intensa actitud emocional. De la revista estadounidense Life se toman también algunas de las caricaturas contrarias al Kaiser. Pegaso contiene igualmente un par de menciones a la colonia o a los sectores germanófilos del país, y un par de notas sobre la posición mexicana, en un caso fomentando el apoyo efectivo a los aliados y en otro caso prefiriendo la neutralidad, según el ejemplo español. Por su parte, en torno a la guerra, van a escribir en la revista autores como Enrique González Martínez, López Velarde, Ramiro de Maeztu, o José Enrique Rodó. Salvo el caso de González Martínez, el tono de esas colaboraciones no es tan germanófobo como el general de la revista, pues algunas de ellas critican por igual a los dos bandos y otras llevan el tema por derroteros propiamente literarios o culturales. ${ }^{10}$ Finalmente, y quizá sea uno de los datos más significativos, ese conflicto bélico queda planteado en términos de la oposición entre el sistema político democrático y el dictatorial o autárquico. El primero estaría representado por los aliados e incluiría también a Estados Unidos e implícitamente México, y el segundo por Alemania y el imperio Austro-Húngaro. De nuevo, una dicotomía política de alcance global, pero tal como la presenta Pegaso, sustentada en una geopolítica claramente transatlántica.

Sin duda alguna otra de las secciones que merece más atención es la publicitaria, tanto en términos cuantitativos como cualitativos. Los anuncios, reclamos y productos mercantiles revelan que la mayor parte de este tipo de transacciones e itinerarios se producen con Estados Unidos, Inglaterra o Francia, y muy pocas veces con España. ${ }^{11}$ Los nombres de muchas de esas compañías, establecimientos y eslogans no dejan lugar a duda: "La Westinghouse Electric \& Manufacturing Co." (I:10), "Phoenix Assurance

10 Indirectamente relacionadas con este tema, se dan las noticias surgidas a raíz de la revolución soviética con opiniones contradictorias o vacilantes acerca del zar y de la política rusa de esos momentos.

Con la elocuente excepción de la publicidad editorial sólo hemos localizado un anuncio comercial con productos españoles, referido al ámbito de la cosmética y la perfumería (I:327)

17. Revista Iberoamericana, Vol. LXXIX, Núms. 244-245, Julio-Diciembre 2013, 929-947 ISSN 0034-9631 (Impreso) ISSN 2154-4794 (Electrónico)
Company Limited"(I:30), “The Canadian Bank ofCommerce"(I:30)y "L'Union de Paris y La Foncière" (I:31); por su lado la zapatería J. Marquez y Cía, asegura tener "el mejor surtido de calzado fino americano" (I:31) y el "Centro mercantil", asegura que vestirá al cliente "como si se vistiese en París" (I:107). Como es de esperar, la publicidad es además el espacio donde más se intensifican las expresiones referidas a la temporalidad presente o a la actualidad más inmediata, bien notificando del arribo reciente de diversas mercancías o bien invitando a los lectores a visitar el comercio "con urgencia" para poder inspeccionar y/o comprar esos productos. Como es de esperar también, en los anuncios de productos tecnológicos como los de la compañía Westinghouse, esa nota de actualidad queda marcada de forma más intensa, hasta el punto de convertirse casi en un símbolo de la oposición entre lo antiguo y lo moderno..$^{12}$ Finalmente, las ilustraciones y siluetas que acompañan esa publicidad remiten también al mismo tipo de itinerarios y trayectorias, como puede ser la Estatua de la Libertad, la figura de Cristóbal Colón al lado de un globo terráqueo o modelos de ropa de indudable origen foráneo, como el frecuente anuncio de canotiers que ofrece la "Casa Tardan".

En consecuencia, tampoco es casualidad que las crónicas sociales o deportivas noten igualmente la fuerte presencia de los mundos francés y anglosajón. Esta impronta es especialmente clara en el nivel lingüístico de las noticias y gacetillas correspondientes, que presenta ese tipo de vocablos en cursivas, como términos todavía foráneos o no completamente asimilados. Las crónicas sociales se llenan de palabras como bar, cocktail o whiskey y las deportivas, que a menudo van firmadas por "Penatly-kick", se inundan de palabras como goal, corner, foul, hands, free kick, goal keeper, football, shuteo, offside, teams, o "encuentros sportivos" (sic). En este caso el lector se encontraría una variante del plurilingüismo del que hablaba Bakhtin, pero también con la constatación de que es el espacio atlántico (cis- y transoceánico) el que estaría protagonizando los intercambios que en ese momento definirían no sólo las relaciones económicas o comerciales entre ambos lados sino ya las más propiamente culturales e identitarias. ${ }^{13}$ La marca de actualidad que llevan las revistas, y en este caso Pegaso, se convierten en un documento único y referencial en este sentido.

12 En concreto me refiero a un anuncio dividido gráficamente en dos columnas, en cuyas cabezas figuran respectivamente las palabras "Ayer..." y "Hoy". Debajo de la primera se lee: "Pérdida de tiempo Pérdida de dinero / Pérdida de salud". Debajo de la segunda: "Ahorro de tiempo / Economía de dinero Garantía de salud" (II:90)

${ }^{13}$ Como ejemplo del proceso de la evolución de la compleja transculturación de México rescato una cita de la crónica "La avenida Madero" de Ramón López Velarde: "Plateros fue una calle, luego una rue, y hoy es una street. No creo lo último" (I:14). Lo estadounidense o "cisatlántico no hispánico" aparece también de otras formas. Además de las noticias referidas a su participación en la guerra, se recogen notas y artículos sobre los museos, sobre la ciudad de Nueva York, sobre algunos episodios históricos comunes, etc. Salvo una columna acerca de la deshumanización que supone el modo de vida estadounidense, las qú por la mediacín que supone la paricipacion estadounidense en la guerra a lado de los aliados.

Revista Iberoamericana, Vol. LXXIX, Núms. 244-245, Julio-Diciembre 2013, 929-947 ISSN 0034-9631 (Impreso) ISSN 2154-4794 (Electrónico) 
Aunque no de modo tan marcado, en una dirección semejante apuntan las gacetillas y noticias insertadas en las secciones "Teatros y cines" y "Vida artística y literaria", secciones que casi siempre se refieren a las artes plásticas o dramáticas, y menos a las propiamente literarias, que suelen aparecer en la sección "Libros y revistas". En las dos primeras secciones, y con la excepción del arte dramático, lo francés y lo anglosajón vuelven a dominar de nuevo. Así, Pegaso recoge notas sobre la vida teatral de Nueva York y la representación de géneros como el vaudeville, la ópera, el ilusionismo, y autores, actores y artistas no hispánicos como Louis Parker, Chaplin, Onofroff, Francisca Bertini o Susana Brandais. Sin embargo, en su conjunto, en suelo mexicano, son mayoritarias las representaciones teatrales de obras españolas -más que mexicanascomo es el caso de las escritas por los Álvarez Quintero, Francisco Villaespesa, Jacinto Benavente, Eduardo Marquina, o Muñoz Seca. Finalmente la presencia de lo español en el ámbito cultural mexicano tiene aún más facetas, según recoge Pegaso. Además de los intercambios literarios y editoriales ya citados, la revista nota el repetido éxito de las llamadas "conferencias españolas", que organiza la colonia española en la capital, en otras ciudades del país, e incluso en otros países hispanoamericanos. En la misma dirección se recuperan o se dan noticias sobre personajes o temas clásicos como la conferencia sobre Cervantes y el romanticismo, otra sobre la pintura de Velázquez, una más sobre Benito Pérez Galdós, o, curiosamente, se presenta Hernán Cortés como figura fundacional del país. Por su parte, el viaje de Alfonso Reyes a la península da como fruto un libro titulado Cartones de Madrid, que es convenientemente anunciado por la editorial Cultura.

Con todo lo anterior queda claro que revistas literarias y culturales como Pegaso suponen un campo privilegiado para ratificar las propuestas de los estudios transatlánticos y estudiar las diferentes formas de su materialización. Las revistas contienen a la vez la pluralidad de discursos que interesa a esa lectura intercultural y también la especia temporalidad en la que conviven esos discursos y que de igual modo se corresponde con la perspectiva ucrónica que define la praxis transatlántica. Esa multiplicidad es siempre abierta y ensanchable, y se resiste a todo tipo de reducciones. Al mismo tiempo esas revistas son naturalmente polifónicas, y de la misma manera que sus diferentes secciones son a la vez dependientes del macrotexto general de la revista y autónomas en sus contenidos, los diferentes núcleos del ámbito transatlántico pueden considerarse también en su interdependencia y en su autonomía particular, es decir, convirtiendo dicho ámbito en un espacio igualmente polifónico. La existencia de revistas análogas pero ubicadas en núcleos geopolíticos y culturales diferentes es otra forma de insistir en esa polifonía propia del espacio transatlántico.

Desde Pegaso se asiste a un continuo y multiforme movimiento de cruces e itinerarios que en diversos niveles ponen en relación a los diferentes escenarios atlánticos, sean éstos hispánicos (España, Hispanoamérica) o no hispánicos (Inglaterra, Francia, Estados Unidos). Esos cruces son siempre multidireccionales y si se pueden adivinar jerarquías

174 Revista Iberoamericana, Vol. LXXIX, Núms. 244-245, Julio-Diciembre 2013, 929-947 \begin{tabular}{lll}
\hline ISSN 0034-9631 (Impreso) & ISSN 2154-4794 (Electrónico)
\end{tabular} en algunos sentidos, como ocurre con algunos movimientos mercantiles, en otros sentidos existen siempre jerarquías inversas, como pueden mostrarlo la existencia de corresponsales de la revista, que convierten a ésta en el centro normativo de la relación, o el fenómeno de las traducciones, que al final siempre resultan en una apropiación textual. En cualquier caso, queda claro que el ámbito y los estudios transatlánticos no pueden dejar fuera el mundo hispánico. Una revista puntual como Pegaso contiene por sí misma suficientes pruebas de que las actividades comerciales y culturales del ámbito anglosajón no pueden definirse sólo en ese ámbito, ya que su verdadero alcance y su dinámica general las hacen completamente interatlánticas. De la misma forma, Pegaso muestra que el ámbito transatlántico hispánico no puede definirse sin relación al anglosajón. Obviamente esta correlación tan plural, donde cada uno de esos dos ámbitos cuenta a la vez con un amplio número de núcleos que pueden funcionar simultáneamente como emisores o receptores, resulta al final en un panorama donde es posible tejer una red de intercambios tan tupida y rica que permite proponer esa pluralidad de interacciones como la verdadera naturaleza (o esencia, si se quiere) del mundo transatlántico.

Por último, el análisis de Pegaso ha constatado que el Modernismo es también un momento "naturalmente transatlántico". Los cruces librescos o editoriales entre el mundo hispánico y el no hispánico de ambas orillas son continuos y se dan también en ambas direcciones. Estudiar desde este contexto la variedad y hondura de todos esos cruces es una de las formas más apropiadas de renovar la crítica y la historiografía modernista. Hay entonces que seguir ahondando en esta vertiente trasatlántica del Modernismo, bien comentando la interacción del modernismo peninsular con los diversos ámbitos cisatlánticos (Francia, Inglaterra) o transoceánicos (Hispanoamérica, Brasil, Estados Unidos) o bien, en la otra orilla, profundizando también en los cruces cisatlánticos y transoceánicos del Modernismo hispanoamericano, con una atención especial a los diferentes niveles de intercambios entre los diferentes países que lo albergaron y de éstos con los Estados Unidos o Brasil. Como se ve las posibilidades combinatorias que ofrecen las correlaciones entre todos esos núcleos geopolíticos y la multiplicidad de discursos y temporalidades que interesan al "modernismo transatlántico" son prácticamente innumerables y, además, aceptan multitud de perspectivas. Por todo ello y ante este panorama, actitudes como el regreso a enfoques neopositivistas o la pretensión de establecer de nuevo una jerarquía cronológica o cualitativa entre el modernismo peninsular y el hispanoamericano se quedan realmente en reivindicaciones anecdóticas o secundarias, muy alejadas de las posibilidades abiertas por la hermenéutica transatlántica.

Revista Iberoamericana, Vol. LXXIX, Núms. 244-245, Julio-Diciembre 2013, 929-947 ISSN 0034-9631 (Impreso) ISSN 2154-4794 (Electrónico) 


\section{OBRAS CITADAS}

Acereda,Alberto. El antimodernismo: debates transatlánticos en el fin de siglo. Palencia: Cálamo, 2011.

"El antimodernismo. Sátira e ideología de un debate transatlántico". Hispania 86/4 (2003): 761-72.

"Ut pictura poiesis: luminismo y modernismo como paradigmas transatlánticos de la modernidad". Cuadernos Americanos 93 (2002): 175-93.

Armitage, David: "Tres conceptos de historia atlántica". Revista de Occidente 281 (2004): 7-28.

Bakhtin, Mikhail. Esthétique et Theorie du Roman. París: Gallimard, 1978. Problems of Dostoevsky's Poetics. Ann Arbor: Ardis, 1973

Bauer, Ralph. "Los grandes cometas de 1680/1681 y la política del saber criollo en la Nueva España y la Nueva Inglaterra”. Revista Iberoamericana LXXV/228 (2009): 697-715.

Beckman, Ericka. "Sujetos insolventes: José Asunción Silva y la economía transatlántica del lujo". Revista Iberoamericana LXXV/228 (2009): 757-72.

Carter, Boyd G., ed. La Revista de América, de Rubén Dario y Ricardo Jaime Freyre. Managua: Imprenta Nacional, 1967.

Castañón, Adolfo. “Alfonso Reyes: de la diplomacia considerada como una de las bellas artes”. México Trasatlántico. Julio Ortega y Celia del Palacio, eds. México: Fondo de Cultura Económica, 2008. 195-208.

Celma Valero, María Pilar. Literatura y periodismo en las revistas del fin de siglo: estudios e índices (1888-1907). Madrid: Júcar, 1991.

Champagne, Rosaria. "Feminism, Essentialism, and Historical Context." Women's Studies 25 (1995): 95-108.

Chemris, Chrystal. "The Pilgrimage 'Topos' and the Problem of Modernity:ATransatlantic View of Selected Hispanic Texts.” Romance Studies 26/2 (2008): 136-49.

Colebrook, Claire. "Ceterau and Foucault: Tactics and Strategic Essentialism." The South Atlantic Quaterly 100/2 (2001): 543-74.

Dabove, Juan Pablo. “'La cosa maldita': Leopoldo Lugones y el Gótico Imperial”. Revista Iberoamericana LXXV/228 (2009): 773-92.

Delaney, Jeane. "Rediscovering Spain: The Hispanismo of Manuel Gálvez". Bridging the Atlantic. Toward a Reassessment of Iberian and Latin American Cultural Ties. Marina Pérez de Mendiola, ed. Albany: SUNY Press, 1996. 71-82.

Díaz y Alejo, Ana Elena, y Ernesto Prado Velázquez. Índice de la Revista Azul, 1894 1896. México: UNAM, 1968.

Escudero, María A. "Hispanist Democratic Thought versus Hispanist Thought of the Franco Era:AComparative Analysis". Bridging the Atlantic. Toward a Reassessment of Iberian and Latin American Cultural Ties. Marina Pérez de Mendiola, ed.Albany: SUNY Press, 1996. 169-86.

Faber, Sebstián. "Fantasmas hispanistas y otros retos transatlánticos". Cultura y cambio social en América Latina. Mabel Moraña, ed. Madrid: Iberoamericana, 2008. 315-45.

Fernández, James D. “America Is in Spain. A Reading of Clarín 'Boroña'.” Bridging the Atlantic. Toward a Reassessment of Iberian and Latin American Cultural Ties. Marina Pérez de Mendiola, ed. Albany: SUNY Press, 1996. 31-44.

Fernández de Alba, Francisco y Pedro Pérez del Solar. "Hacia un acercamiento cultural a la literatura hispano-americana". Iberoamericana VI/21 (2006): 99-107.

Fogelquist, Donald F. Españoles de América y americanos de España. Madrid: Gredos, 1968

Fuchs, Barbara, y Yolanda Martínez-San Miguel. “La grandeza mexicana de Balbuena y el imaginario de una 'metrópolis colonial'”. Revista Iberoamericana LXXV/228 (2009): 675-96

Gabilondo, Joseba. "Introduction. Special Section: The Hispanic Atlantic." Arizona Journal of Hispanic Cultural Studies 5 (2001): 91-113.

“Genealogía de la 'raza latina': para una teoría atlántica de las estructuras raciales hispanas". Revista Iberoamericana LXXV/228 (2009): 795-818.

Gerasi-Navarro, Nina. "Conflictos imperiales: la mirada de Frances Calderón de la Barca”. Revista Iberoamericana LXXV/228 (2009): 735-55.

Golubov, Nattie. "La crítica literaria feminista contemporánea: entre el feminismo y la diferencia". Debate Feminista 9 (1994): 116-26

Gutiérrez, José Ismael. Perspectivas sobre el modernismo hispanoamericano. Madrid: Pliegos, 2007. 119-60.

Gutiérrez Mouat, Ricardo. "Postdictaduray crítica cultural transatlántica". Iberoamericana $\mathrm{VI} / 21$ (2006): 133-50.

Gutiérrez Nájera, Manuel. Obras I. Crítica literaria. Erwin K. Mapes y Ernesto Mejía Sánchez, eds. México: UNAM, 1959.

Hill, Ruth. "Entre lo transatlántico y lo hemisférico: los proyectos raciales de Andrés Bello". Revista Iberoamericana LXXV/228 (2009): 719-36.

Ita Rubio, Lourdes de. "Imágenes de México en la Inglaterra de los Tudores. La Nueva España en la obra de Richard Hakluyt”. México Transatlántico. Julio Ortega y Celia del Palacio, eds. México: Fondo de Cultura Económica, 2008. 91-131.

Katra, William. "Spain in the Thought of the Argentine Generation of 1837." Bridging the Atlantic. Toward a Reassessment of Iberian and Latin American Cultural Ties. Marina Pérez de Mendiola, ed. Albany: SUNY Press, 1996. 57-70.

Letral 5 (2010): 1-29. Diciembre 2010. <http://www.proyectoletral.es/revista/\#void> 15 enero 2011.

Mainer, José Carlos, ed. En el 98 (Los nuevos escritores). Madrid: Visor, 1997.
Revista Iberoamericana, Vol. LXXIX, Núms. 244-245, Julio-Diciembre 2013, 929-947 ISSN 0034-9631 (Impreso) 
Mannin, Susany Andrew Taylor, eds. Transatlantic Literary Studies. A Reader. Baltimore: Johns Hopkins UP, 2007.

Mataix, Remedios. "El Caribe es otro Mediterráneo (O la condición trasatlántica al lezámico modo)". Letral 4 (2010): 1-14.

Mejías-López, Alejandro. The Inverted Conquest. The Myth of Modernity and the Transatlantic Onset of Modernism. Nashville: Vanderbilt UP, 2010.

Merediz, Eyda M.y Nina Gerassi-Navarro. "Introducción: confluencias de lo transatlántico y lo latinoamericano". Revista Iberoamericana LXXV/228 (2009): 605-36.

"De Insulis o más islas que se repiten: Canarias, Cuba y el Atlántico Hispano". Revista Iberoamericana LXXV/228 (2009): 865-84.

Miller, Gavin. "Scotland's Authentic Plurality: The New Essentialism in Scottish Studies." Scottish Literary Review 1/1 (2009): 157-74

Ortega, Julio, ed. Nuevos hispanismos interdisciplinarios y transatlánticos. Madrid/ Frankfurt: Iberoamericana, 2010.

"Cervantes y Sor Juana: la hipótesis del Barroco". Hispanic Review 74/2 (2006) 165-180.

Ortega, Julio y Celia del Palacio, eds. México Trasatlántico. México: Fondo de Cultura Económica, 2008.

Patai, Daphne. "El esencialismo de Clarice Lispector". Nuevo Texto Crítico 3/1 (1990): 21-35.

Pegaso. Revista Ilustrada. Enrique González Martínez, Ramón López Velarde y Efrén Rebolledo, eds. 2 vols. México: Fondo de Cultura Económica, 1979.

Pineda Franco, Adela. Geopoliticas de la cultura finisecular en Buenos Aires, París y México. Las revistas literarias y el modernismo. Pittsburgh: IILI, 2006.

Pérez de Mendiola, Marina. "Going Transatlantic: Toward an Ethics of Dialogue." Chasqui 35 (2006): 3-10.

ed. Bridging the Atlantic. Toward a Reassessment of Iberian and Latin American Cultural Ties. Albany: SUNY Press, 1996.

"The Universal Exposition Seville 1992: Presence and Absence, Remembrabce and Forgetting." Bridging the Atlantic. Toward a Reassessment of Iberian and Latin American Cultural Ties. Marina Pérez de Mendiola, ed. Albany: SUNY Press, 1996. 187-204.

Quevedo, Amalia. De Foucault a Derrida: pasando fugazmente por Deleuze y Guattari, Lyotard, Baudillard. Pamplona: EUNSA, 2001.

Robbins, Jill y Johnson Roberta. "Introduction: Rethinking Spain From Across the Seas." Studies on 20th and 21st Century Literature 30/1 (2006).

Santiáñez-Tió, Nil. "Temporalidad y discurso histórico. Propuesta de una renovación metodológica de la literatura española moderna". Hispanic Review 65/3 (1997): 267-90. ISSN 0034-9631 (Impreso) ISSN 2154-4794 (Electrónico)
Schwartz, Jorge y Patiño, Rosa. "Introducción: revistas literarias/culturales latinoamericanas del siglo XX". Revista Iberoamericana LXX/208-209 (2004): 647-50

Smith, Paul Julian. "Los estudios cinematográficos y televisivos: localismos y transnacionalidad". Nuevos hispanismos interdisciplinarios y transatlánticos. Julio Ortega, ed. Madrid: Iberoamericana, 2010. 149-60.

Snead, Jennifer. "Print, Predestination, and the Public Sphere: Transatlantic Evangelical Periodicals, 1740-1745." Early American Literature 45/1 (2010): 93.

Stevens Arroyo, Anthony M. "Jaime Balmes Redux: Catholicism as Civilization in the Political Philosophy of Pedro Albizu Campos." Bridging the Atlantic. Toward a Reassessment of Iberian and Latin American Cultural Ties. Marina Pérez de Mendiola, ed. Albany: SUNY Press, 1996. 129-52.

Valdés, Héctor. Indice de la Revista Moderna. Arte y Ciencia (1898-1903). México: UNAM, 1967

Venegas, José Luis. “Unamuno, Epistolarity, and the Rethoric of Transatlantic Hispanism.' MLN 124/2 (2009): 438-59.

Voigt, Lisa. "La 'historia verdadera' del cautiverio y del naufragio en los imperios ibéricos". Revista Iberoamericana LXXV/228 (2009): 657-74.

Zuleta, Ignacio. La polémica modernista: el modernismo de mar a mar (1898-1907). Bogotá: Instituto Caro y Cuervo, 1988.
Revista Iberoamericana, Vol. LXXIX, Núms. 244-245, Julio-Diciembre 2013, 929-947 ISSN 0034-9631 (Impreso) 
